\title{
A CASE OF CEREBRAL MUCORMYCOSIS DIAGNOSED IN LIFE, WITH EVENTUAL RECOVERY
}

\author{
BY \\ AUGUSTIN MURESAN \\ From the Institute of Medicine and Department of Pathology, Colentina Hospital, Bucharest, Rumania
}

(RECEIVED FOR PUblication AUgUSt 19, 1959)

A case of mucormycosis lozalized in the brain is reported in a subject aged 18 years who was not suffering from diabetes. As the patient displayed symptoms of cerebral compression he was operated upon and a cystic formation was excised.

Microscopic examination disclosed the presence of hyphae, displaying the characteristics of mucor, in chronic granulation tissue. The mycelia had a tendency to develop in the vessels and to invade them, and a structure very similar to a sporangium could be observed. Some of the mycelia had undergone dystrophic calcification.

The patient has been kept under medical supervision for two and a half years since the operation and appears to have completely recovered.

During the past years numerous cases of human mucormycosis have been diagnosed and its frequent association with diabetes mellitus has been noted. In animals (mice, rats), alloxandiabetes has been shown to enhance the development and spread of mucor.

The brain is considered to be an infrequent site for mucormycosis. So far 17 instances have been recorded, in 13 of which it appeared to have occurred as a result of spread from the orbital cavities and from the paranasal sinuses (Bauer, Ajello, Adams, and Useda Hernandez, 1955; LeCompte and Meissner, 1947; Foushee and Beck, 1956 ; Gregory, Golden, and Haymaker, 1943 ; Gunson and Bowden, 1955 ; Jackson and Karnauchow, 1957 ; Kurrein, 1954 ; Long and Weiss, 1959; Martin, Lukeman, Ranson, and Geppert, 1954; Merriam and Tedeschi, 1957 ; Muresan, 1956 ; Paltauf, 1885 ; Stratemeier, 1950 ; Torack, 1957 ; Wolf and Cowen, 1949). Diabetes mellitus was found to be present in 10 of the cases. Post-mortem cultivation of the fungus was successful only in the case of Bauer et al. (1955). An exclusively cerebral localization, in the absence of any apparent involvement of other tissues, either local or elsewhere in the body, has not so far been described.

\section{Case Report}

The patient, an 18-year-old male hairdresser who lived in a village, had been suffering from headache, giddiness, and vomiting for about three weeks. Slight fever was present. He had involuntary movements of the lower limbs and a progressive decrease of muscular strength in the upper limbs. There were no labyrinthine symptoms, but papillary stasis was found to be present. He was referred to a neurosurgical department with a tentative diagnosis of brain tumour and found to have signs of compression in the left parietal area. The cerebrospinal fluid was slightly xanthochromic. Papillary stasis and papilloedema progressively increased and haemorrhagic patches appeared. Laboratory tests yielded no pathological findings. Operation was decided upon.

The suspected area was approached by trepanation and an intracerebral cystic formation, the size of a nut, with turbid, reddish contents, was excised. The peripheral zone of the cyst, of a reddish colour, resembled tumour tissue and the possibility of an astrocytoma was considered.

The post-operative course with penicillin treatment was uneventful and the patient left hospital six weeks after the operation. Insignificant post-operative functional disorders gradually subsided and after six months the patient resumed his occupation. When re-examined two and a half years after the operation, he appeared to have completely recovered and was pursuing his normal vocation.

Microscopical Examination of the Operation Specimen.-The outer part of the specimen was reddish and relatively soft. It enclosed a well-defined cavity displaying a smooth inner surface. Numerous fragments of the tissue surrounding the cavity were examined microscopically. Certain portions consisted of inflammatory granulation tissue containing sparse calcospherites. In these areas, numerous branched, non-septate hyphae of a tubular appearance (Fig. 1) 


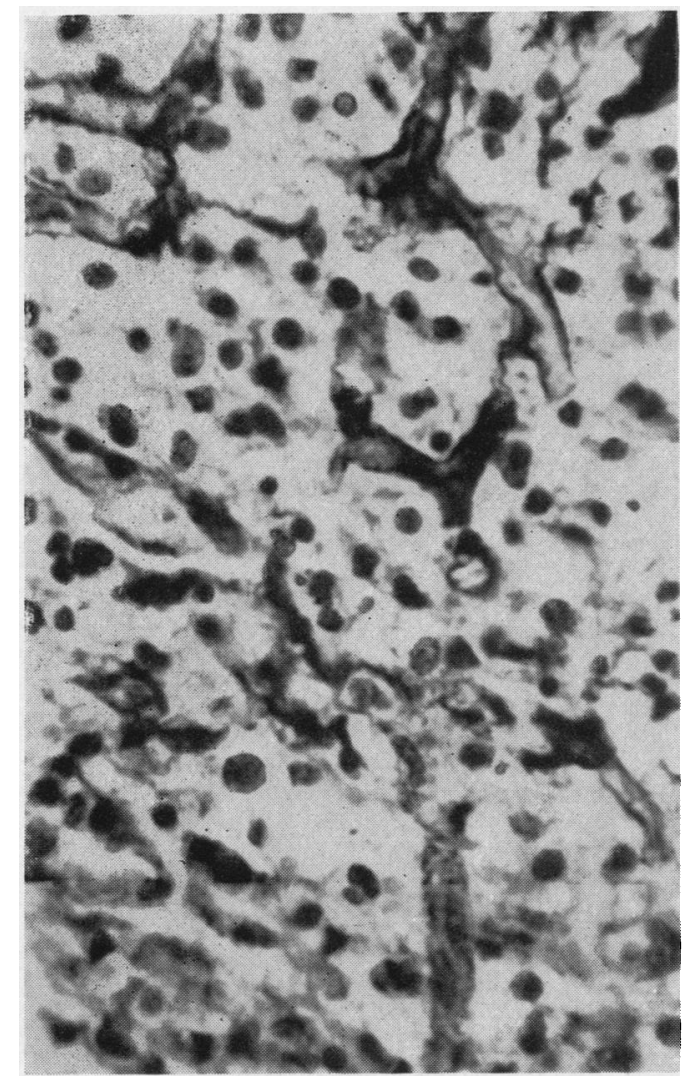

Fig. 1.-Numerous cleat branched, non-septate hyphae in nonspecific chronic inflammation tissue. Haematoxylin-eosin stain. $\times 400$.

were found. They were often seen to be crowding around the vessels, the walls of which they tended to invade (Fig. 2). Some of the hyphae attained a length of $200 \mu$ (including their branchings). The endings of the branches were irregular or somewhat round, displaying no terminal swellings. A sharply outlined ovular swelling containing roundish structures was found in a single instance. In all probability this was a sporangium (Fig. 3).

As a rule, the fungus hyphae could be uniformly stained by Mayer's haematoxylin and by the Hotchkiss-MacManus method. In some areas, however, the hyphae were seen to be shorter and more condensed, electively staining with haematoxylin as a consequence of dystrophic calcification (Fig. 4). Calcospherites were to be found in the same areas and the inflammatory tissue exhibited a tendency to fibrosis.

Owing to the tentative diagnosis of cerebral tumour the specimen for microscopic examination had been fixed in formol. Thus, inoculations on culture media were impracticable and the fungus could not be

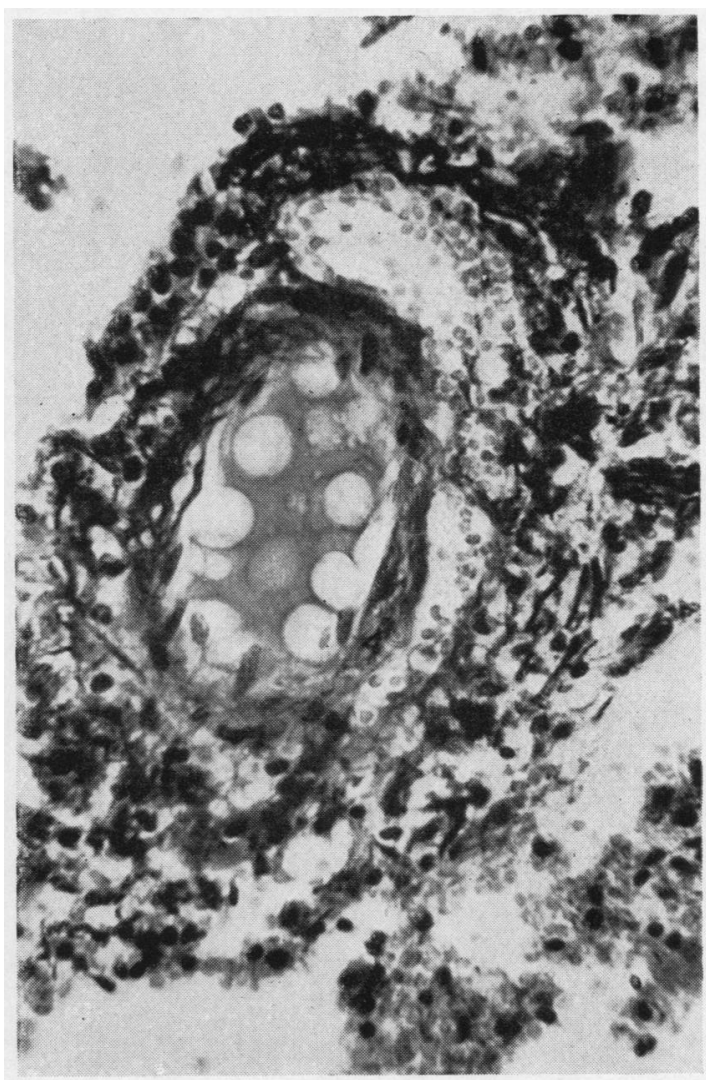

Fig. 2-The hyphae electively develop around the vessels and display a tendency to invade their walls. Haematoxylin-eosin stain. $\times 200$.

classified precisely. Nevertheless it may be inferred from the morphology of the mycelia that the fungus was a member of the family Mucoraceae.

\section{Comment}

The clinical course and the histopathological findings suggest that in the present case mucormycosis was localized in the inflammatory tissue surrounding a cystic cavity. The fungus probably penetrated into the brain from some other inapparent localization (probably on the nasopharyngeal mucosa or in the upper air passages), whence it was conveyed to the brain via the blood or the lymph. It may be inferred that the cystic cavity in the brain parenchyma followed a focus of softening which was later transformed into a cyst. Very probably the filaments of the fungus, which tend to develop around the vessels and to invade them (see Fig. 2), caused thrombosis of a cerebral vessel resulting in an ischaemic focus and 


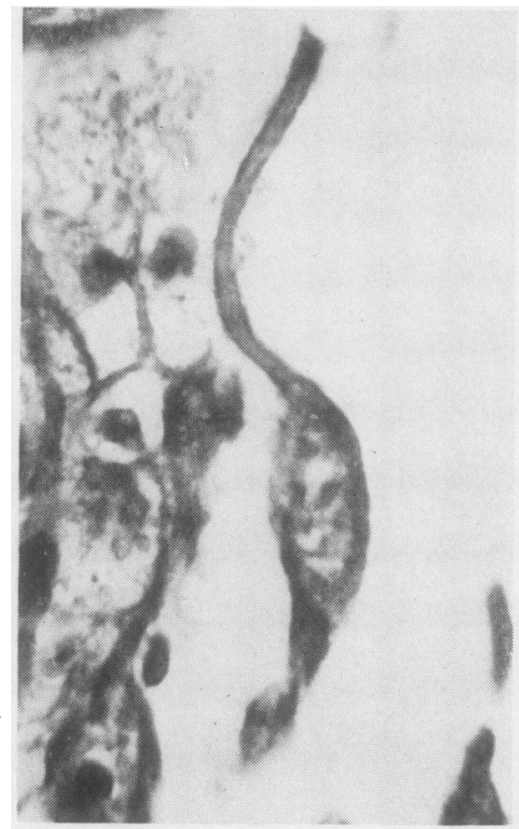

Fig. 3.-A hypha with an oval ending containing sporulated structures (sporangium). Haematoxylin-eosin stain. $\times \mathbf{4 0 0}$.

subsequent cystic softening. The fungus continued to develop around the cystic cavity.

The chronicity of the microscopic appearance of the inflammatory process in the area containing fungous hyphae was confirmed by the presence of calcospherites in these areas. Some of the fungous hyphae showed signs of necrobiosis as shown by their calcareous impregnation and by retraction of their margins. It has been shown that calcification of mycelia in the tissues can also occur in cases of chronic histoplasmosis (Muresan, 1956).

A fungous hypha exhibiting a structure similar to the sporangium (Fig. 3) was identified, a'though not as clearly as in culture media. Mucor sporangia are characterized by the presence of a columnella at the point where the hypha enters the sporangium. This structure was not visible in our microscopical preparations, but, in the opinion of mycologists, the columnella is not seen in all sporangia, even in culture media. Sporangia in the tissues have been observed in other cases of mucormycosis, but only Paltauf (1885) has described them in the nervous system. In other cases of cerebral mucormycosis only filamentous branching mycelia were found.

The interest of this case lies in the fact that it demonstrates the possibility of an elective

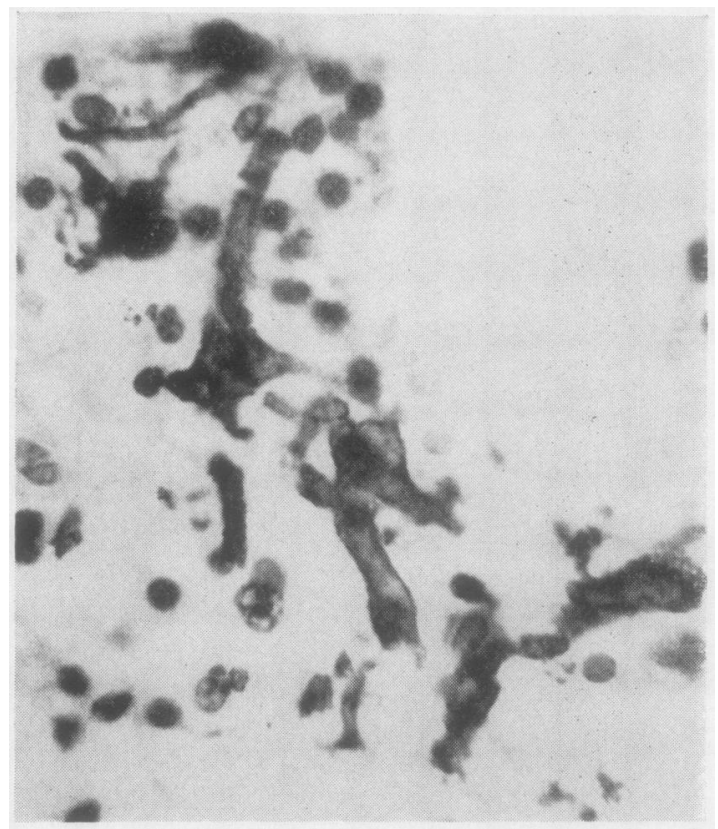

Fig. 4.-Branched hyphac exhibiting areas of dystrophic calcification and irregular margins. Haematoxylin-eosin stain. $\times 400$.

localization in the brain or other tissues, as the patient recovers after operation, even in the absence of specific antifungal treatment. Also it appears that enhancing conditions (diabetes, leukaemia, antibiotic and cortisone treatment) are not of paramount importance, as has been suggested. Certain microscopic patterns of the development of the fungus in the nerve tissue in this case show that the evolution may be prolonged and that the condition may be well tolerated up to the time when it results in appreciable neurological disorders.

\section{REFERENCES}

Bauer, H., Ajello, L., Adams, E., and Useda Hernandez, D. (1955) Amer. J. Med., 18, 822

Foushee, S., and Beck, W. C. (1956). N.C. med. J., 17, 26.

Gregory, J. E., Golden, A., and Haymaker, W. (1943). Bull. Johns Hopk. Hosp., 73, 405.

Gunson, H. H., and Bowden, D. H. (1955). A.M.A. Arch. Path., $60,440$.

Jackson, J. R., and Karnauchow, P. H. (1957). Canad. med. Ass. J., 76,130 .

Kurrein, F. (1954). J. clin. Path., 7, 141.

LeCompte, P. M., and Meissner, W. A. (1947). Amer. J. Path., 23, 673 .

Long, E. L., and Weiss, D. L. (1959). Amer. J. Med., 26, 625.

Martin, F. P., Lukeman, J. M., Ranson, R. F., and Geppert, L. J. (1954). J. Pediat., 44, 437.

Merriam, J. C., and Tedeschi, C. G. (1957). Neurology, 7, 510

Muresan, A. (1956). (Sem. Hôp. Paris), Path. Biol., 4, 1465.

Paltauf, A. (1885). Virchows Arch. path. Anat., $102,543$.

Stratemeier, W. P. (1950). Arch. Neurol. Psychiat. (Chicago), 63, 179.

Torack, R. M. (1957). Amer. J. Med., 22, 872.

Wolf, A., and Cowen, D. (1949). J. Neuropath. exp. Neurol., 8, 107 